\title{
Using the MODO in Capital Expenditure
}

\author{
Carraro, N. C. ${ }^{1}$; Lima, C. R. C. ${ }^{2}$; Oliveira, E. C. ${ }^{*}$
}

\author{
${ }^{1}$ Department of Management, Federal University of São Carlos, São Paulo, Brazil - UFSCar/CCN-LS \\ ${ }^{2}$ Department of Production and Systems Engineering, University Methodist of Piracicaba, São Paulo, Brazil. \\ 3*Department of Management, Federal University of São Carlos, São Paulo, Brazil - UFSCar/CCN-LS
}

\begin{abstract}
The study presents a methodology for the analysis of new investments in property, plant and equipment from the use of operational performance objectives as a premise for decision-making. Qualitatively, we used the product of this study operations performance matrix. The matrix was then applied through a survey of a sample of footwear companies in the region of Jaú, state of São Paulo, Brazil. The correlations between the scores obtained for each operational performance objective were tested. The analysis of the regression coefficients associated to each independent variable (quality, reliability, speed and flexibility) allowed to conclude that all the questions had a positive impact on the dependent variable (costs), indicating a positive correlation. This survey demonstrated the utility of the proposed methodology when using as a premise for decision the performance objectives of operations that demonstrated that the dependent variable is the consequence and not the cause as treated in the conventional investment analysis that uses the cash flow logic and value present as a decision factor. However, the methodology presented as a complementary form is the analysis of investments of this nature in relation to techniques widely used by the market that adopt the financial results projected as critical success factors.
\end{abstract}

Keywords-Capital Expenditures, Operations Strategy, MODE, Competitive Positioning, Decision Making.

\section{INTRODUCTION}

The definitions of competitive positioning go through the operations strategy in order to identify the performance objectives of operations capable of generating competitive advantages. Therefore, decision-making at the time of the acquisition of fixed assets (IA) requires special attention, since machinery and equipment can become obsolete quickly due to the reduction of the lifetime of the products, as a result of globalization and an increasingly larger economy competitive.

Due to the capital they have, large companies have invested millions in the acquisition of IA, capable of generating differentiated products due to the application of disruptive and / or sustained technology, which guarantees product differentiation and even a considerable competitive advantage. These companies use advanced techniques of financial, economic, operations management and project engineering to succeed in the acquisition of new IA [1] [2] [3] [4].

However, for smaller companies, acquiring new IA may become a problem due to lack of structure and knowledge in management techniques.

Of course, these investments arise from the need for growth, from the obsolescence and natural wear and tear of machines and equipment, vehicles, among others. In most cases, the technique used for decision-making is the comparison of the expenditure necessary for the acquisition in the present moment in function of future financial returns [5]. To say that the value of a firm is equal to the value of its projected cash flows, discounted at an appropriate rate, leaves many practical questions open [6].

Therefore, IA acquisitions should not only take into account financial returns, but also the competitive benefits that this new IA can provide [7] [8]. Gains with flexibility, speed, quality, reliability and low cost have been advocated as a way to generate competitive benefits. When the decision-making in the acquisition of IA does not pass through these analyze, the relationship of the company with its continuity will be aggravated. On the contrary, when the decision goes beyond the financial return, it allows the company to observe and review its operational power [9].

From the study of the operations strategy, the analysis of the operations performance objectives are fundamental elements for the maintenance of the business activities and consequently the definition of its competitive position [10] [11] [12]. This analysis has been used and recommended from a variety of perspectives, including IA acquisitions, when seeking means of guiding the decision is very important once the capital is used, repentance can be costlier. To know the processes of evaluation of investments in IA, to seek maturity by the managers, potentiates returns, reducing costs and increasing profitability [13].

Several forms and formulas have been proposed for this orientation and analysis to occur, causing managers to 
make decisions that favor the pursuit of achievable operations performance objectives through the acquisition of new IA. Examples are the demand flow chart, earnings and risk analysis, the cross-matrix of performance targets, the investment certification index and the operational performance index. In all of them the performance objectives of operations are placed as a critical success factor in acquiring an IA. However, we observed in these discussions a gap arising from a combinatorial sequence of applications that would culminate with a methodology proper to the expected purpose [14] [15] [16] [17] [18]. In this work, the main objective of this work is to use the principles of the operations strategy to expand the analysis of the IA acquisitions. In order to do so, we advocate the creation of an instrument to survey the necessary items for the evaluation of qualitative variables or critical success factors, which, afterwards, should be submitted to quantitative analysis, generating a logical argumentative sequence as a means of reflection and complement to the techniques of financial analysis already existing and consolidated by the market.

The gain with this methodology is the analysis on the current and future stage of the operations performance objectives from the acquisition of new IA. In this sense, whenever this methodology is applied, a quantitativequalitative analysis will be carried out in order to evaluate the alignment of this new acquisition with the objectives by which the company positions itself in the market and competes. Therefore, this analysis may demonstrate opportunities and alternatives for your user.

In the analysis of the recent market scenarios it is evident that the competitiveness between companies has required constant investments in IA. Many companies apply resources to improve operational efficiency, better shareholder return, customer loyalty, as well as the definition of a better competitive position, investing in the best technologies and equipment available, and incorporating modern business management techniques, maximizing the use of tangible and intangible resources [3].

Another reason for new investments in fixed assets is due to the great need for new products, which causes the current product life cycle to become smaller and smaller. In the past, the need for new products was lower and, consequently, the life cycle was higher, requiring less investment in substitutes [14]. Organizational markets change constantly, demanding from their suppliers more quality, fair prices, speed and, above all, added value [19].

The need to invest in AI has led some researchers to conclude that the valuation of these investments should not only take into account financial decisions [7] [8].

\subsection{Operations Strategy}

The strategy of operations is less related to individual processes and more to the business as a whole, more concerned with changing scenarios and business, and how operations need to give rise to these changes, providing the basis for a sustainable advantage. One way of quantifying this contribution is to identify the level of operations and the capacity required. The result of positive decisions in this context turns into a performance that generates certain competitive benefits [2].

Studies have proven the significance of the operational performance objectives in a survey applied in Iranian industries, creating an operational model that established the necessary relationship between the corporate strategy and the operations strategy [20]. It has been proven that this alignment is significant and distinguishes successful companies from unsuccessful ones, highlighting seven types of alignments, resulting in a model that associates alignment with organizational performance.

Many companies fail to realize that the lack of alignment between tangible and intangible resources reduces their capabilities. Some researchers point the cause to this gap as the market-based view where many companies are guided by marketing. In this sense, the subsystems would be weakened and the operational capacity of the company would tend to generate lower performance and, consequently, to generate less competitive benefits [9] [21] [22].

Competitive benefits are classified in three stages, the first being the order qualifier, where you have the basic attributes that a product or service must possess for the purpose of participating in a market, however, you will only be assured a positive performance if these characteristics make up the so-called order-winning factors, in which customers see the key conditions for their acquisition. Attaining a maximum performance, we have the so-called surprise, given its condition of assigning to the client advantages previously not conceived [2].

Therefore, in order to achieve these competitive benefits, the organization as a whole must be imbued with the same objective, and in this sense, the acquisitions of IA must add up to the operational result, not only in terms of reducing labor costs or maintenance, but also with respect to other operations performance objectives such as efficiency, flexibility, quality, speed, reliability, determined by their interaction with the other subsystems of the company. These objectives of operations performance will allow the company to achieve the desired competitive benefits contrary to the thesis that the results to be generated by an IA is its net present value discounted from acquisition and maintenance costs. 
Therefore, going beyond the financial return as a way of measuring the contributions coming from acquiring an IA is a preponderant factor for the authors mentioned above. In this sense, it is fundamental to understand how the operational performance objectives can be used at the time of acquisition to evaluate what competitive benefits or what contributions may generate the IA that will be integrated with the company.

\subsection{Operations performance objectives}

There are many costs that could be avoided if the operational performance objectives had been analyzed before acquiring an IA. For example, the setup of a machine that interferes with speed and production flexibility [24]. Thus, operations performance objectives directly interfere in the goal termed costs, deducing that these are not the cause, but rather the consequence [25]. In this way, operations strategies should be focused as competitive differentials, analyzing the operational performance objectives, where costs (initial, operation and maintenance), quality (durability, customer perception), flexibility (capacity to change bulk, products and processes) will be the differentials capable of generating the competitive benefits necessary to achieve the desired performance [26]. This set that integrates the importance of the operations strategy was proven by survey studies from 2008 to 2013, demonstrating that these are the attributes studied by researchers in four decades [22].

Figure 1 demonstrates the necessary relationship between the performance objectives of operations related to internal and external aspects as a way of increasing the capabilities of the companies.

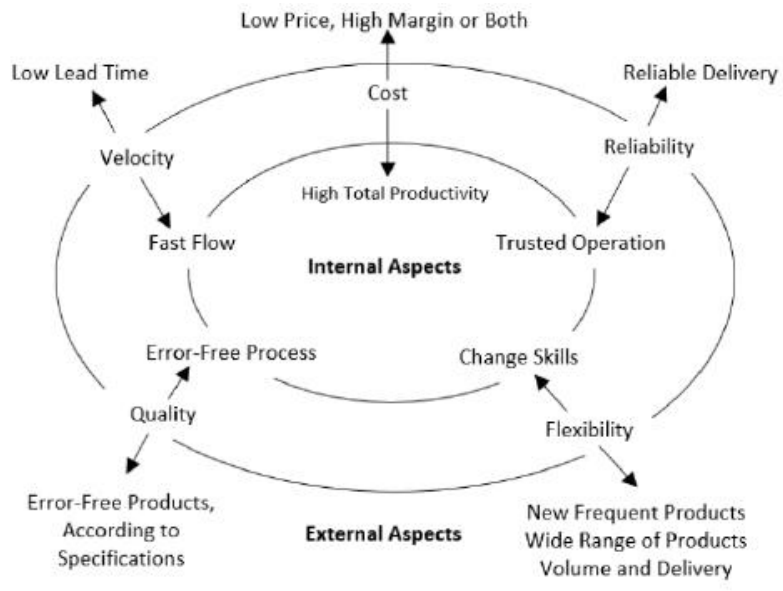

Fig.1: Alignment between internal and external aspects of performance objectives.

Fonte: Adapted from Slack and Lewis (2008).

Quality is something desired by every consumer of products and services and must be generated from the production process. This basic principle refers to the fact that the productive process must create efforts to generate quality. In this sense, machines and equipment must allow this goal through three stages: elimination of losses, elimination of causes of losses and optimization of processes [27].

Quality must be achieved by operations generating skills to deliver products and services reliably and consistently. This study has proven through information about corporate reputation in hundreds of companies analyzed in Fortune magazine, that quality is intrinsically linked with innovation and profitability, but quality alone is not capable of generating innovation and profitability.

If a company manages to combine quality with speed it will have a good competitive advantage. In this sense an IA must have the ability to foster the delivery of products and services with quality and speed. To calculate the process lead time it is only to measure the productprocess-hour relationship, dividing the number of products in the process by the number of finished products per hour. However, to associate speed and quality, lead-time must be measured by dividing by the number of value-added steps [28]. This vision corroborates the strategy of operations that has as a definition for speed the time of customer service, respecting their need from the request to the delivery of products and services [2].

The speed gained with the new IA will allow two macro performance goals, which are: inventory formation and timely delivery. As inventory formation, although there are techniques to minimize this item, because it is understood that they consume resources due to idleness, even so, even fewer, will be necessary for many business activities [27]. In this sense, speed will allow higher stock indices, higher production rates, faster delivery methods, more realistic promises, better order production control, and better information systems.

Quality and speed without the addition of the performance goal of operations called reliability is meaningless, and this should not be confused because speed is used meaning keeping promises of delivery honor the delivery time given to the customer in quantity, price, between other attributes agreed in the negotiation [2]. Overall reliability is intrinsically associated with IA reliability, which tends to be lower throughout its operational life, even with all the maintenance excellence that can be applied [14].

Another virtue that an IA should have is flexibility while ODO. Flexibility describes the ability of a manufacturing plant to be useful for different production tasks, and the smaller the re-ordering efforts required between orders, the greater the flexibility [29], since it has to be able to 
respond quickly the needs of customers [17]. For this, it is fundamental that equipment and machines allow two conditions: the flexibility of the product and the flexibility of the volume. The flexibility of the product is to identify the ability of the production system to rapidly change production from one product to another. Volume flexibility, on the other hand, indicates the capacity to increase or reduce the volume of production without thereby increasing fixed costs in the same proportion.

It is not only low cost that promotes a company or product, but, rather, the union of product mix, positioning and production, which are conditions that will be achieved with a good strategic dimension and with an adequate level of investments. The criticis $m$ is related to the incessant pursuit of low cost, deteriorating the other objectives of operations performance. In many repositions or acquisitions of IA what determines decision-making is the volume of production and the low cost of production, without considering other competitive benefits that the IA can generate. Thus, it is important to note that an IA can contribute not only to reducing operating costs, but also to promoting the quality, speed, reliability and flexibility necessary for production and the company as a whole. This alignment should be traced by the operations strategy and should be a long-term corporate view [22].

In this way, maintaining the conditions to adapt to the laws of the market is fundamental and, in that sense, the observance of these precepts through the objectives of operations performance before the investment in IA is fundamental. Therefore, this step has to be consistent and systematized.

\subsection{Evaluation of acquisitions in IA}

Investment projects are often complex. In order to understand the various aspects involved in decisionmaking, it is customary to construct models. Models are simplifications of reality, which sin for simplifications, but bring huge gains in operational aspects. A model of monetary flows, occurring punctually at the end of periods, is a simplification of one of the financial dimensions of an acquisition project in IA [6].

It is through Capex that most IAs are requisitioned in organizations, that is, it is the formal mechanism that conveys the needs of acquisitions of assets demanded by the business activity as a whole, mainly by the industrial production. Capex or investment in capital goods is the amount of resources spent on the acquisition of goods and reinvestments in a company [31].

The criticism regarding the capital budget and consequently Capex is that they take into account, as critical factors of success and investment decisionmaking, the net result of the project and its rate of return, without considering a measure of alternative sensitivity or else transform the value of money which is a ne-order polynomial that does not have a single root in a new equation with $n$ roots [32] [33].

For each of these approaches, there are additional alternatives that help to determine the final value or value creation, and that there is no better model, but a model appropriate to the scenario or characteristics of the company or asset being evaluated [5]. No traditional method of investment analysis meets, in isolation, all the criteria for a decisive selection of projects of different natures. This restricts the use of mono-objective functions as a form of optimization for the capital budget process [34].

The capital budget rules that use the concept of net present value as a decision factor, deconstructing the model and indicating that complementary analyzes should be performed, since finance theory should not be used as a flow chart in the investment decision, but only as a vector for the decision to invest inIA, were severely criticized [35].

The capital budget should contemplate the investment proposals in IA, aligning them with the strategic planning. Criticism is on the condition that larger, non-daily projects tend to be more information than smaller projects, however, the cause of organizational mis matches may be due to lack of intersection. The author advocates auditing for both types of projects, focusing on the information subsidy for both [12].

Therefore, creating a trail for analyzing acquisitions inIA is fundamental in any proportion, be it at the replacement or strategic level, since, in fact, what most companies have used is a budget that generates autonomy for a particular business unit, and this is not necessarily aligning goals with the operations performance objectives that guide the organization. Repeated acquisitions without this compliance could lead a company to have performance problems in a short time [36].

\section{PROPOSAL}

This work is limited to developing a methodology to analyze investments in IA from the use of theory on operations strategy. An additional contribution is sought that assists in decisions oriented towards the achievement of objectives that allow a better competitive performance, generating the continuity of the business activities.

Documentary and bibliographical research was used for the construction of knowledge through a systematic reading of part of the existing literature, including theses, articles and books. The survey was also used as a means to gather opinions and information from a population - 
which will be identified in the next section - through a questionnaire [37].

Once the documentary and bibliographical research was done, the objectives of the operations performance that the IA was to achieve were established, being instrumented by the Matrix of Operational Performance Objectives (MODO) presented in Table 1. The MODO is the fruit of this research work and was the instrument used in the applied survey, whose results will be presented and discussed later.

The survey was used to identify the tangible and intangible benefits of acquiring specific equipment. The survey questions were elaborated according to the alignment that the equipment should present in relation to the current and future competitive positioning adopted by the companies. It seeks to understand the understanding that this acquisition will bring from the point of view of quality, speed, reliability, flexibility and costs, among other performance objectives of operations to be listed by the company.

The survey carried out with MODO was only the first step, since, afterwards, quantitative tests with greater power of response should be applied to the pertinence of each questioning. The number of performance objectives of operations to be used in the survey should be coherent with those desired competitive benefits, therefore, keeping in relation to the number of lines represented by the measures to measure the internal and external benefits

To measure the reliability of the items created for the MODO, the test called Cronbach's Alpha was applied. This test is often used in empirical research involving multi-item tests, covering latent random variables, for example, quality assessment of a questionnaire with a latent profile metric. The alpha should be interpreted as a squared correlation coefficient, where, for example, a result of 0.75 should correspond to a $75 \%$ real impact of the variables. In a first phase the MODO was applied experimentally in the sample aiming at its validation. At this stage, with the data collected, the reliability and unidimensionality of each of the operations performance objectives were verified [38].

In the next step, the correlation between the scores obtained for each operational performance objective was analyzed using Pearson's Correlation Coefficient and regression models. The Pearson correlation coefficient, which varies between -1 and 1 , is a measure of linear association between continuous variables. Values close to 1 (in absolute value) indicate a strong as sociation between variables and, close to zero, indicate absence of association. Positive values indicate that the variables vary in the same direction and negative ones that vary in the opposite direction [39].

Table 1: Operations Performance Objectives Matrix (MODO)

Evaluation Potential Competitive Benefits of IA Operations Performance Objective: Quality

\begin{tabular}{|c|c|c|c|}
\hline $\begin{array}{c}\text { Potential Internal } \\
\text { Benefits }\end{array}$ & Score & $\begin{array}{c}\text { Potential External } \\
\text { Benefits }\end{array}$ & Score \\
\hline \multicolumn{4}{|c|}{ Performance Objective: Speed } \\
\hline $\begin{array}{c}\text { Potential Internal } \\
\text { Benefits }\end{array}$ & Score & $\begin{array}{c}\text { Potential External } \\
\text { Benefits }\end{array}$ & Score \\
\hline \multicolumn{4}{|c|}{ Operations Performance Objective: Reliability } \\
\hline $\begin{array}{c}\text { Potential Internal } \\
\text { Benefits }\end{array}$ & Score & $\begin{array}{c}\text { Potential External } \\
\text { Benefits }\end{array}$ & Score \\
\hline \multicolumn{4}{|c|}{ Operations Performance Objective: Flexibility } \\
\hline $\begin{array}{l}\text { Potential Internal } \\
\text { Benefits }\end{array}$ & Score & $\begin{array}{c}\text { Potential External } \\
\text { Benefits }\end{array}$ & Score \\
\hline \multicolumn{4}{|c|}{ Operations Performance Objective: Costs } \\
\hline $\begin{array}{c}\text { Potential Internal } \\
\text { Benefits }\end{array}$ & Score & $\begin{array}{c}\text { Potential External } \\
\text { Benefits }\end{array}$ & Score \\
\hline
\end{tabular}

Source: Adapted from Slack and Lewis (2008).

This coefficient, although it allows to evaluate the degree of association between continuous variables, does not allow to define a cause-effect relation. This type of relationship - the form with a variable is influenced by one or more variables - is possible with regression models. These models allow us to study relations of functional dependence between one or more independent variables and a dependent variable [40]. This method was applied to evaluate how the four items (speed, quality, flexibility, quality - independent variables) influenced the cost (dependent variable) question.

In addition, we used exploratory factor analysis, regression analysis and score analysis. However, if the objective is to compare two devices, the Student's T-Test for paired samples or the non-parametric Wilcoxon test for paired samples should be used if the conditions for the first application are not met [41]. If the objective is to compare three or more devices, the repeated measures ANOVA or the non-parametric Friedman test should be used if the conditions for ANOVA application are not met [38].

The scoring analysis for each operational performance objective was performed using descriptive statistics. Although statistically primary, it provided an overview of each objective, combining all results for a general 
analysis that was compiled at the time of the decision and sent to the simulation of economic and financial results.

\section{RESULTS AND DISCUSSION}

To validate the methodology presented in the previous section, a survey was carried out with a large sample of footwear manufacturers in the region of Jaú, State of São Paulo, Brazil, with 45 items listed and 31 respondents, according to Figure 2. The evaluation occurred in acquisition of an IA for automated cutting of leather, which is the upper part of the footwear. This equipment is of fundamental importance for an industry of this sector and contemplates among other all the objectives of operations performance presented in the theoretical foundation.
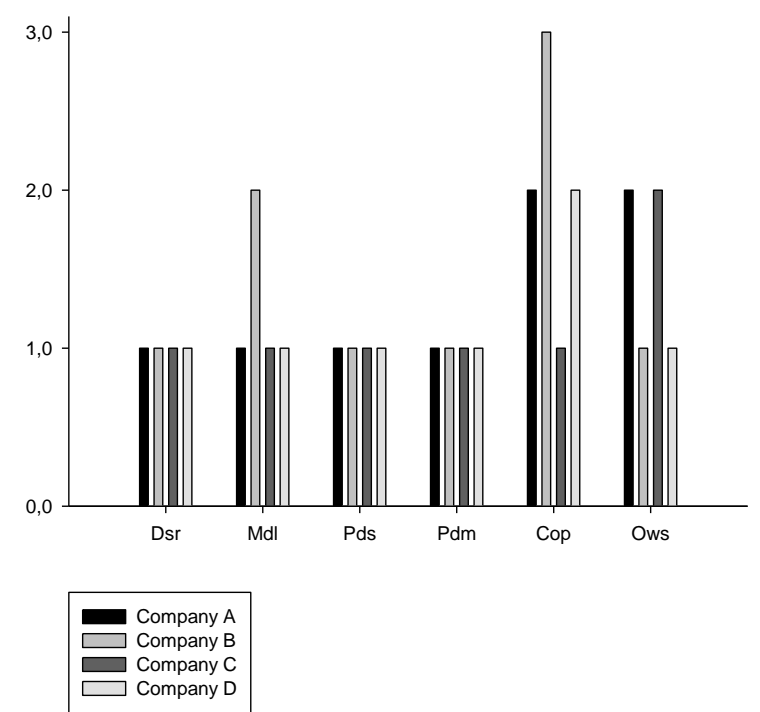

Fig.2: Operational function respondents.

Subtitle: Dsr: Designer; Mdl: Modeler; Pds: Production Scheduler; Pdm: Production Manager; Cop: In Charge of Production; Ows:Owners.

The MODE produced for this survey took into account all literature covering the operations strategy, considering only the generic performance objectives [2]. Because there were several companies, there were no specific is sues or concerns about the strategic alignment adopted by them. The initial concern was to validate the method generically.

Nine questions were elaborated for each generic goal of operations performance, seeking to identify potential internal and external benefits. As demonstrated each objective influences the result of another and consequently in the result of operations of the company. Therefore, in the construction of the MODO care was taken to create questions that were related only to the performance objective itself.
Once the Cronbach's Alpha was applied for the reliability and the origin of each question [38], the obtained answers were compiled and taken to the SPSS software for statistical analysis according to the sequence shown in the section dealing with the proposal. This was the time to chart a general analysis to identify whether the IA has adherence to the generic objectives of operations performance.

As a synthesis of the analysis of these answers, a global score was obtained as presented in Table 1 . This was the first step of the results that the SPSS software produced and which was the result of a primordial analysis, since if the median and the standard deviation did not reach considered satisfactory, all underlying analyzes would be compromised.

\begin{tabular}{lccccc}
\hline Questions & $\begin{array}{c}\text { Minimu } \\
\text { m }\end{array}$ & Maximum & Mediana & Medi & $\boldsymbol{\alpha}$ \\
& 5.00 & 7.00 & 6.00 & 6.00 & 0.77 \\
Quality & 4.00 & 7.00 & 6.00 & 5.84 & 0.86 \\
Velocity & 5.00 & 8.00 & 6.00 & 6.00 & 0.89 \\
Reliability & 5.00 & 7.00 & 6.00 & 6.00 & 0.77 \\
Flexibility & 5.00 & 7.00 & 6.00 & 5.94 & 0.81 \\
Costs & 5.00 & 7.00 & 6.00 & 5.84 & 0.52 \\
Global & & & & & \\
Score* & \multirow{2}{*}{5} & & &
\end{tabular}

Table 1: Overall score and each item of the MODE $(\mathrm{N}=$ 31).

Analyzing the descriptive statistics that gave rise to Table 1 , we reached a consolidated scenario where the mean (5.84) and median (6.00) were slightly above the center point of the scale (5), indicating that the acquisition of the equipment would have a positive impact in all operations performance objectives. All scores had median scores of 6 and near average scores ranging from 5.84 (Speed) to 6.00 (Quality, Reliability and Flexibility), indicating that the respondents also valued the impact of each item on the equipment acquisition. It can be deduced that the analysis by score resulted in the principle composed by Equation 1.

$$
M O D O=\sum_{t=1}^{n} \frac{A I}{\mu O D O} \leq M d O D O
$$

\section{Equation (1): MODO Setting}

For the interpretation of Equation 1 it is considered as numerator the IA that will be evaluated. As the denominator, the average of the operational performance objectives obtained by the overall score. The result of this equation should be less than or equal to the overall score 
of the median of the operations performance targets. The higher the results, the better the evaluation. Therefore, and in agreement with the idea that intangible benefits will only be useful if they can be converted into tangible benefits, since the operational benefits have already been treated, it is important to extend the analyzes to the economic dimension, and a regression analysis is performed.

In the regression analysis it was intended to study the influence of the performance objectives of operations denominated Quality, Speed, Reliability and Flexibility (independent variables) on Costs (dependent variable). Using the same software and the same database, the results are presented in Table 2.

Table 2: Results of the regression model $(N=31)$.

\begin{tabular}{|c|c|c|c|c|c|}
\hline \multirow{2}{*}{$\begin{array}{l}\text { Independent } \\
\text { Variables }\end{array}$} & \multicolumn{2}{|c|}{$\begin{array}{l}\text { Non-standard } \\
\text { Coefficients }\end{array}$} & \multirow{2}{*}{$\begin{array}{c}\begin{array}{c}\text { Standard } \\
\text { Coefficients }\end{array} \\
\text { B }\end{array}$} & \multicolumn{2}{|c|}{ Test $\mathbf{T}$} \\
\hline & B & $\begin{array}{l}\text { Default } \\
\text { Error }\end{array}$ & & $t$ & $P$ \\
\hline Constant & 0.643 & 0.870 & & 0.739 & 0.466 \\
\hline Quality & 0.234 & 0.089 & 0.346 & 2.635 & 0.014 \\
\hline Velocity & 0.143 & 0.075 & 0.236 & 1.904 & 0.068 \\
\hline Reliability & 0.300 & 0.082 & 0.513 & 3.672 & 0.001 \\
\hline Flexibility & 0.193 & 0.094 & 0.286 & 2.059 & 0.050 \\
\hline Model & \multicolumn{5}{|c|}{$\begin{array}{l}\text { Dependent Variable: Costs } \\
\mathrm{R}=0.785 ; \mathrm{R}^{2}=0.616 \\
\mathrm{~F}(4 ; 26)=10.447 ; \mathrm{p}<0.001\end{array}$} \\
\hline
\end{tabular}

The techniques used are corroborated by studies [39] [40] in showing that the model is significant $(F(4 ; 26)=$ $10,447 ; \mathrm{p}<0.001)$, with the independent variables explaining $61.6 \%$ of the Costs question $(\mathrm{R} 2=0.341)$. The analysis of the regression coefficients associated to each independent variable allowed to conclude that all the questions have a positive impact on the Cost variable, indicating that an increase in the scores of the questions causes an increase in the score Costs. The reliability performance $(B=0.300, \beta=0.513, p=0.001)$ had $a$ stronger impact on the dependent variable Costs, followed by Quality $(\mathrm{B}=0.234, \beta=0.346, \mathrm{p}=0.014)$, Flexibility $(\mathrm{B}=0.193, \beta=0.286, \mathrm{p}=0.050)$ and velocity $(\mathrm{B}=0.143$, $\beta=0.236, p=0.068$ ). Therefore, the results show that these variables consist of a set and should be treated as such to achieve competitive differentials, corroborated by other studies [26].

For each operational performance objective, nine questions were listed. The reliability was the objective that had the highest consideration in the analys is by score and in the coefficients of regression. Thus, the quality and expected speed in the equipment are justified by this ranking in the analysis [2]. Respondents understood the questionings made that there will be elimination of losses, elimination of causes of losses and optimization of processes, as well as the speed of delivery at the right time for the customer [11] [27].

As for the flexibility to have a median score in the overall analysis and especially in relation to the standard deviation, being also the penultimate one in the regression analysis, it is justified because of the flexibility to describe the ability of a plant and not only of an equipment [29]. As the equipment tested is for cutting the leather, other production sectors such as assembly and finishing were not analyzed. Thus, it is understandable the results achieved, since respondents understood by MODO that this equipment alone would not have the capacity to generate flexibility and speed to the point of being considered in isolation as generating a potential internal or external benefit.

In view of the issues listed for this research, it was demonstrated by the results that, initially, the set of operations performance objectives had favorable aspects and generated potential internal and external benefits. It was observed that the cost variable was explained to a great extent by the other variables. Thus, according to results from other studies [25], in which costs are not the cause, but rather the consequence, it became evident which of the objectives could burden or cancel this acquisition. In this sense, MODO and its treatment helped managers to understand the relationship between the expenditures required for the new acquisition and the economic result arising from the generation of potential internal and external benefits for each operational performance objective, against the increase of profitability, as an expected result in the acquisition of a new IA [13] [7] [8].

In this way, it is fundamental that a good theoretical bas is be used to defend the questions applied in MODO, that these questions are proved pertinent through the statistical tests demonstrated in this section, that the survey application has a consistent target population and that, mainly, the analyzes of the results are by statistical tests and subsequently submitted to the financial evaluation, as shown in Figure 3, which illustrates a sequence for this analysis, proposing the application of techniques of evaluation of investments already widely used by the market [5] [32] [33] [34]. 


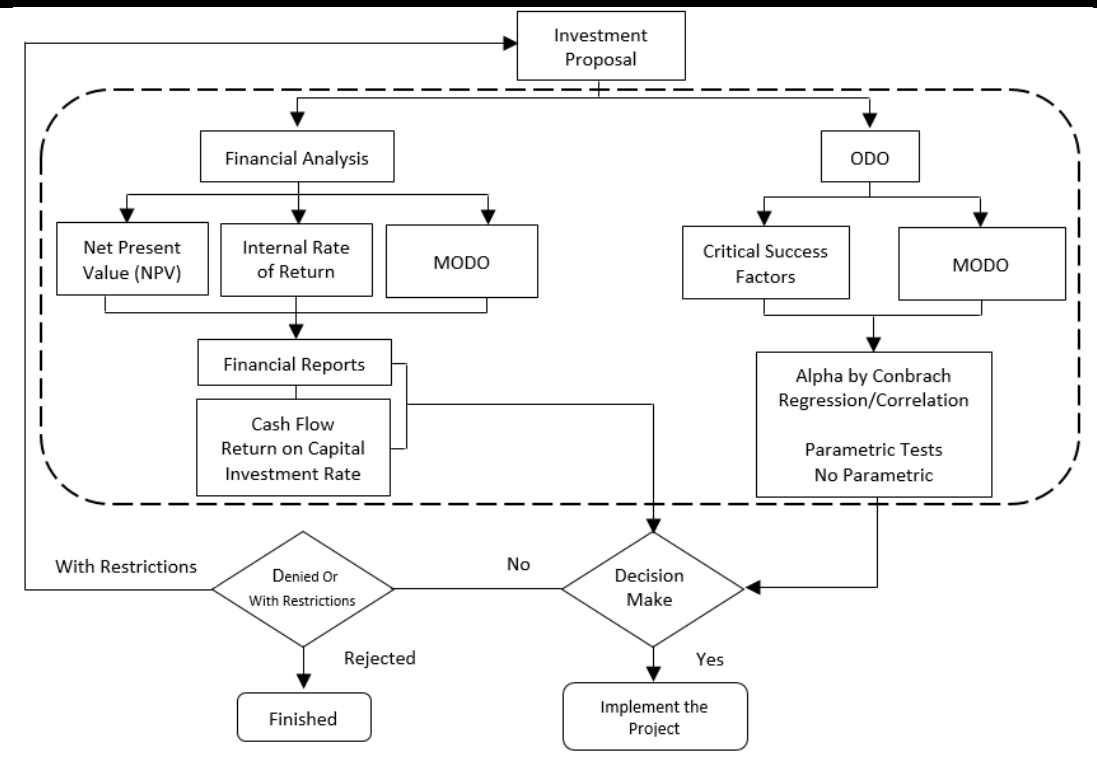

Fig.3: Sequence for analysis of IA acquisitions

The proposed methodology goes against the criticism given in other studies [6], since the value of a company is not equal to the value of its projected cash flows discounted at an appropriate rate, but rather its capacity to gather resources and transform them in capacities [9]. In this regard, when reviewing concepts about operations strategy, operations performance objectives and potential internal and external benefits when acquiring a new IIA, the company is placing first its need to remain active in the market, seeking the necessary performance to be considered as the winner of the request and even surprise [2], thus defining its competitive position [10] [11] [12]. The proposal of this work, summarized in Figure 3, addresses a gap arising from a combinatorial sequence of applications that culminates with a methodology for acquiring an IA according to notes made in previous studies [14] [15] [16] [17] [18] [20]. These techniques will allow you to prove which IA will integrate more monetary results for the company. They are fundamental to prove the competitive benefits achieved by the ODO due to the acquisition of a new IA and how they will impact monetarily on the company's cash flow. Therefore, these vectors that traditionally are the main ones in the decision of investment, end up being consolidated also by a previous analysis from the perspective of operational gains. Thus, through the questioning applied in the MODO, the primary condition has to be positive, only then to be submitted to financial evaluation.

\section{CONCLUSION}

With the objective of demonstrating the relevance of the operations strategy in the evaluation in the acquisition of IA, this work resulted in a methodology with applicability of the MODO, which contemplates qualitative and quantitative methods in the definition of the performance objectives of operations and potential internal and external benefits.

The proposed methodology presents a different analysis of what is practiced by the market, because counter to the cash flow to present value as a decision factor, compels the company to reflect how that new IA will be integrated to the plant and its productive layout.

This search has occurred due to many criticisms presented in the literature through the way companies acquire or replace their IA, mainly due to the great changes that have occurred in the world market, where, increasingly, products have a shorter life cycle.

The proposal and the sequence of analysis presented in this paper are not rigid and therefore may be adapted to the needs of the company as well as to the conditions of acquisition. However, it is recommended to adopt a methodological rigor in the preparation of the MODO, as well as in its analysis through the statistical tests presented.

The use of MODO assumes that it will drive the user's efforts to a definition of their competitive positioning by analyzing the performance objectives of operations that their physical subsystem can generate. This analysis opens a new window for managers to identify and quantify what competitive performance they want to achieve.

Even without access to the financial data of the companies participating in the survey, however, through the operational data obtained through MODO, it was possible to correlate the alternatives to the independent variables (quality, speed, reliability and flexibility), with the dependent variable (cost), which will greatly facilitate the identification of results in the financial analysis 
already established, because its executors will know the source of the costs.

Another important aspect in relation to MODO is that it uses the opinion of several actors regarding the IA that will be acquired. Thus, in large companies where divisional accounting exists, one can have aggregate values from the view of these actors who do not necessarily need to belong to that unit alone. This practice overthrows the thesis that the capital budget is plastered and passive of manipulation. Thus, for the as sembly of a unit score and also a global score, it is fundamental to represent the will and the knowledge of those involved in the operational, tactical and strategic processes of a company.

As future contributions, it is expected that further work will re-discuss the importance of evaluating operations strategy, operational performance objectives, and potential internal and external benefits in acquiring IA. These, in turn, are part of a universe called the physical subsystemthat interacts with other subsystems in order to achieve corporate objectives and goals.

It is also suggested combining this discussion with the Balanced Scorecard (BSC). Although it has not been addressed in this paper, the theory about the BSC is widely known in the market. In this way, the operational performance objectives could be used as perspectives for the construction of a strategic map. Thus, the company over time would have a control panel on the performance achieved from the existing IA, choosing the priorities in acquiring new IA. Incorporating the divisional BSC into the corporate BSC would contribute to a broader understanding of how the physical subsystem should be composed to continue competing.

Another technique widely used by the market and that can be expanded by MODO is the measurement of the Economic Value Added (EVA). By adapting to the BSC, a strategic financial map could also be constructed to demonstrate which IA is creating value, that is, a ranking would be created to demonstrate quantitatively the overrun of the cost of capital spent on the acquisition plus depreciation and maintenance as a function of the lifetime. The more productive the equipment is beyond the cost mentioned, the greater the aggregate economic value it would generate. This practice would take a new score into the analyzes promoted for MODO, adding value to its analytical capacity.

It should be emphasized that this work did not aim to minimize the techniques already used by the market, nor the dynamics applied to investment projects. However, a cut within this horizon is presented, demonstrating the importance of ODO analysis in the acquisition of new IA. It is defended that all good technique is applied. In this sense, MODO is added to existing techniques.

\section{REFERENCES}

[1] E. Borgonovo and L.Peccati. The importance of assumptions in investment evaluation. International Journal of Production Economics, v. 101, pp. 298, 2006.http://dx.doi:10.1016/j.ijpe.2005.01.009.

[2] N. Slack and M. Lewis. Operations Strategy. 2nd ed. Harlow / Prentice Hall, 2008.

[3] D. G. Sirmon, M. A.Hitt, R. D. Ireland and B. A. Gilbert. Resource orchestration to create competitive advantage. JOM - Journal of Management, v. 37, n. 5, pp. 1390-1412, 2011. http://dx.doi.org/10.1177/0149206310385695.

[4] B. Klingenberg, R. Timberlake, T. G.Geurts and R. J. Brown. The relationship of operational innovation and financial performance: a critical perspective. International Journal of Production Economics, v. 142, pp.317-323, 2013. http://dx.doi.org/10.1016/j.ijpe.2012.12.001.

[5] A. Damodaram. Corporate finance. 2. ed. New York: John Wiley, 2001.

[6] T. Copeland, T.Koller, and J. Murrin. Valuation: Measuring and Managing the Value of Companies, 3rd Edition Publisher: John Wiley \& Sons, Inc.; 3 edition, 2000.

[7] B. S. Bernanke, C.Bertaut, L. P. DeMarco and S.Kamin. International capital flows and the returns to safe assets in the United States: 2003 - 2007. International Finance Discussion Papers, n. 1014, 2011.

[8] A. K. Ozdagli. Financial leverage, corporate investments, and stocks returns. The Review of Financial Studies, v. 25, n. 4, pp. 1033-1069, 2012. http://dx.doi.org/10.1093/rfs/hhr145

[9] J. Barney, J. Firm resource and sustained competitiveadvantage. Journal of Management, v. 17, n. $1, \quad$ pp. $99-120, \quad 1991$. http://dx.doi.org/10.1177/014920639101700108.

[10] N. Slack. The importance-performance matrix as adeterminant of improvement priority. International Journal of Operations \& Production Management, v. 14, n. 5, pp. 59-75, 1994.http://dx.doi.org/10.1108/01443579410056803.

[11] H. J. Cho and V.Pucik. Relationship betweeninnovativeness, quality, growth, profitability and market value. Strategy Management Journal. v.26, pp.555-575, 2005. http://dx.doi.org/10.1002/smj.461.

[12] D. Kim. Capital budgeting for new projects: on the role of auditing in information acquisition. Journal of 
Accounting Economics, v. 41, pp. 257, 2006. http://dx.doi.org/10.1016/j.jacceco.2006.03.001.

[13] P. Hofmann and G. Reiner. Drivers for improving supply chain performance: an empirical study. International Journal of Integrated Supply Management, v. 2, n. 3, pp. 214-230, 2006. http://dx.doi.org/10.1504/IJISM.2006.008594.

[14] R. Beach, A. P.Muhlemann, D. H. R. Price, A. Paterson and J. A Sharp. A review of manufacturing flexibility. European Journal of Operational Research, v. 122, n. 1, pp. 41-57, 2000. http://dx.doi.org/10.1016/S0377-2217(99)00062-4.

[15] A. J. Davies and A. K.Kochhar. Manufacturing best practice and performance studies: a critique. International Journal of Operations \& Production Management. v. 22, n. 3, pp. 89-305, 2002. http://dx.doi.org/10.1108/01443570210417597.

[16] M. Ketokivi and R. G. Schroeder. Manufacturing practices, strategic fit and performance: a routinebased view. International Journal of Operations \& Production Management, v. 24, n. 2, p. 171-191, 2004.

http://dx.doi.org/10.1108/01443570410514876.

[17] S. Jayaswal, E.Jewkes and S. Ray. Product differentiation and operations strategy in a capacitated environment. European Journal of Operational Research, v. 210, n. 3, p.716-728, 2011. http://dx.doi.org/10.1016/j.ejor.2010.11.028.

[18] N. C. Carraro, G. B.Gemente and C. R. C. Lima. Development of a model based on financial and operating metrics for investment decisions. In: XIX International Conference on Industrial Engineering and Operations Management, 2012, Valladolid. Anais do ICIEOM 2012, 2012. http://www.abepro.org.br/biblioteca/icieom2012 sub mission 84.pdf.

[19] N. Kumar, L.Scheer and P. Kotler. From market drive to market driving. European Management Journal. v. 18, n. 2, pp. 129-142, 2000. http://dx.doi.org/10.1016/S0263-2373(99)00084-5.

[20] S. K. Shavarini, H.Salimian, J.Nazemi and M.Alborzi. Operations strategy and business strategy alignment model (case of Iranian industries). International Journal of Operations \& Production Management, v. 33 (9) pp. 1108-1130, 2013. http://dx.doi.org/10.1108/IJOPM-12-2011-0467.

[21] S. Gagnon. Resource-based competition and the new operations strategy. International Journal of Operations \& Production Management, v. 19, n. 2, pp. 125-138, 1999. http://dx.doi.org/10.1108/01443579910247392.
[22] N. C. Carraro and C. R. C. Lima. Competitive advantages and operations strategy: scientific production analysis in the period from 2008 to 2013. Asian Journal of Business and Management Sciences, v. 3, pp. 42-50, 2014. http://www.ajbms.org/articlepdf/3ajbms 05201403122 842.pdf.

[23] H. R. Hayes and G. P. Pisano. Beyond world-class: the new manufacturing strategies. Harvard Business Review, 72, 77-86. 1994. https://hbr.org/1994/01/beyond-world-clas s-the-newmanufacturing-strategy.

[24] S. Nakajima. Introduction to Total Productive Maintenance, Productivity Press. Cambridge, MA, 1988.

[25] J. K. Shank and V.Govindarajan. Strategic cost analysis of technological investments. Sloan Management Review, v. 34, n. 1, pp. 39, 1992. http://search.proquest.com/openview/7582fd389cf81 a66f6447ac3efb $15 \mathrm{cf} 7 / 1$ ?pqorigsite $=$ gs cholar\&cbl $=1817083$.

[26] D. A. Garvin. Manufacturing strategic planning. Management Review, California, v. 12, n.2., 1993. http://dx.doi.org/10.2307/41166756.

[27] S. Cai and Z. Yang. On the relationship between business environment and competitive priorities: the role of performance frontiers. International Journal of Production Economics, v. 151, n. 1, pp. 131-145, 2014. http://dx.doi.org/10.1016/j.ijpe.2014.02.005.

[28] M. L. George. Lean six sigma. New York: McGrawHill, 2002.

[29] J. Bengtsson and J.Olhager. The impact of the product mix on the value of flexibility. The International Journal of Management Science, v. 30, n. $4, \quad$ pp. 265-273, 2002. http://dx.doi.org/10.1016/S0305-0483(02)00034-8.

[30] U. S. Karmarkar. Integrative research in marketing and operations management. Journal of Marketing Research, v. 33, pp. 125-133, 1996. http://dx.doi.org/10.2307/3152141.

[31] S. A. Ross, R. W. Westerfield and J. F. Jaffe. Corporate finance. 6 ed. McGraw Hill, 2002.

[32] M. Osborne. A resolution to the NPV - IRR debate? The Quarterly Review of Economics and Finance, v. 50, n. 2, pp. 234-239, May, 2010. http://dx.doi.org/10.1016/j.qref.2010.01.002.

[33] M. Percoco and E.Borgonovo. A note on the sensitivity analysis of the internal rate of return. International Journal of Production Economics, v.135, n. $1, \quad$ Jan, 2012. http://dx.doi.org/10.1016/j.ijpe.2011.09.002. 
[34] E. Bas. A robust approach to the decision rules of NPV and IRR for simple projects. Applied Mathematics and Computation, v. 219, n. 11, pp. 5901-5908, 2013. http://dx.doi.org/10.1016/j.amc. 2012.12.031.

[35] C. A. Magni. Investment decisions in the theory of finance: Some antinomies and inconsistencies. European Journal of Operational Research. v. 137 pp. 206-217, 2002. http://dx.doi.org/10.1016/S03772217(01)00033-9.

[36] B. Bogsnes. Implementing Beyond Budgeting: Unlocking the Performance Potencial. 3. ed. New York: Wiley, 2016.

[37] R. K. Yin. Case study research: design and methods. 4. ed. Thous and Oaks, 2009.

[38] J. W. Osborne. Best Practices in Quantitative Methods. Sage P. I. CA. 2008.

[39] M. Norusis. SPSS 16.0 Statistical Procedures Companion. 2 ed. Prentice Hall. NJ. 2008.

[40] W. B. Nelson. Accelerated Testing: Statistical Models, Test Plans, and Data Analysis. Wiley Interscience. N.J. 2004.

[41] J. F. Hair, W. C. Black, B. J. Babin and R. E. Anderson. Multivariate data analisy. 7. ed. Englewood Cliffs: Prentice Hall, 2010. 